\title{
AS POLIITICAS PÚBLICAS DE LAZER NA MEDIAÇÃO ENTRE ESTADO E SOCIEDADE: POSSIBILIDADES E LIMITAÇÕES'
}

\author{
MS. KENI TATIANA VAZZOLER AREIAS \\ Mestre em educação física pelo Centro de Educação Física e Desportos da \\ Universidade Federal do Espírito Santo (Vitória - Espírito Santo - Brasil) \\ e-mail: kenivazzoler@yahoo.com.br \\ DR. CARLOS NAZARENO FERREIRA BORGES \\ Professor do Programa de Pós-graduação em Educação Física \\ Universidade Federal do Espírito Santo (Vitória - Espírito Santo - Brasil) \\ e-mail: carlos.nazareno@pq.cnpq.br
}

\begin{abstract}
RESUMO
Esse estudo foi realizado na Universidade Federal do Espírito Santo e se constituiu na tentativa de avaliar o Programa Esporte e Lazer da Cidade (PELC) a partir de sua eficiência, eficácia e efetividade social (BELLONI; MAGALHÃES; SOUZA, 2003). Utilizamos como indicador um dos elementos apresentados por Marcelinno (200 I) como fundamental nesse tipo de análise: a concepção que os gestores têm de lazer. Para tanto, tomamos como referência as diretrizes provenientes do Ministério do Esporte e as ações implementadas no município de Vitória-ES, buscando identificar a concepção de Lazer que norteia as ações.
\end{abstract}

PALAVRAS-CHAVE: Políticas públicas; lazer; direito social; avaliação.

I. O estudo em questão fez parte de um projeto de pesquisa intitulado "As Políticas Públicas de Esporte e Lazer no Espírito Santo: abordagem qualitativa e quantitativa" que foi apoiado e financiado pelo Ministério do Esporte, através da Rede CEDES. 
trabalho apresentado diz respeito a uma temática bastante atual e que vem ocupando gradativamente espaço na mídia e na pauta dos gestores públicos do país, a saber, as Políticas Públicas de Esporte e Lazer. Quando revisamos a literatura, encontramos em Marcelinno (200I) que Políticas Públicas para este setor devem ser avaliadas em sua qualidade, em função de três aspectos: a concepção de Lazer dos gestores, a formação dos agentes e a intersetorialidade das ações. ${ }^{2}$

Quanto ao primeiro aspecto, Mascarenhas (2003) reforça que a concepção de lazer dos gestores deve superar a visão funcionalista que o coloca submisso às funções de descanso (recuperação para o trabalho) e entretenimento, tornando-se uma possibilidade concreta de atingir o status de direito social.

O segundo aspecto que afeta o desenvolvimento da política, ressaltado por Marcellino (2002) é a formação do quadro de profissionais. Este aspecto é considerado como um dos maiores entraves à implementação de políticas públicas, pois as disputas internas entre funcionários, a ausência de cargos e funções bem definidas ou a incapacidade técnica, podem implicar na degradação das ações.

Quanto a intersetorialidade das ações no desenvolvimento da Política Pública voltada ao lazer, Marcellino (200 I) afirma que as políticas devem se constituir como ações planejadas e executadas de forma coletiva pelos diversos setores da administração pública, com participação das instituições representativas da sociedade.

Além dos aspectos acima expostos, encontramos outros relacionados à avaliação de Políticas Públicas em geral. Nesse sentido, Belloni, Magalhães e Souza (2003), contribuem ao afirmar que esse tipo de avaliação deve levar em conta a eficiência, eficácia e efetividade social.

A eficiência diz respeito ao grau de aproximação entre o previsto e o realizado, no sentido de combinar os insumos e implementos necessários à consecução de resultados visados, economizando esforços (UNITRABALHO apud BELLONI; MAGALHÃES; SOUZA, 2003). Já a eficácia diz respeito à maximização do rendimento de cada ação, sendo resultado da combinação entre a eficiência da instituição como um sistema e a habilidade em conseguir recursos e subsídios necessários à execução do projeto.

2. Uma análise mais detalhada acerca dos aspectos da formação dos agentes e da intersetorialidade das ações a partir do PELC, pode ser encontrada em Roeldes, Borges e Veunturim, (2009) e Venturin e Borges (20 I0), respectivamente, ambos resultantes de pesquisas desenvolvidas pelo Centro de Estudos em Sociologia das Práticas Corporais e Estudos Olímpicos (CESPCEO), grupo ao qual também estamos vinculados. 
No que se refere à efetividade social, Belloni, Magalhães e Souza (2003) afirmam que, dentre outros fatores, deve-se verificar a forma e as condições em que ocorre a participação dos setores sociais envolvidos, seja na concepção, seja na gestão da política, ou no potencial de mudança presente nas ações implementadas, examinando também a interação das ações propostas com outras políticas governamentais.

A avaliação de políticas e programas sociais como campo de pesquisa social, inicia-se nos Estados Unidos da América (EUA), a partir de 1960. Marcada por um viés comportamental e neutralista, volta-se para a eficiência (menor recurso, maior resultado) e eficácia (metas atingidas) das políticas, não considerando princípios, fundamentos e conteúdos substantivos. No Brasil, a expansão dessas avaliações ocorre na década de 1980 marcada pelo crescimento e pressão dos movimentos sociais. No entanto, mostra-se ainda restrita ao objetivo de controle de gastos (SILVA, 200 I).

Se consideradas numa perspectiva de cidadania, as avaliações de políticas públicas podem se constituir em importante instrumento para o controle social. Correia (2002), afirma que a compreensão de controle social pode estar relacionada tanto ao controle do Estado sobre a sociedade, perspectiva que privilegia os interesses da classe dominante, quanto ao controle da sociedade sobre as ações do Estado, perspectiva que possibilita a explicitação dos conflitos existentes no seio da sociedade civil.

Partindo dos pressupostos teóricos até aqui apresentados que de alguma forma se relacionam com a avaliação das Políticas Públicas, pensamos em destacar um dos aspectos apontados por Marcelinno (200 I ) e relacioná-lo às recomendações consideradas por Belloni, Magalhães e Souza (2003).

Desta forma, apareceu-nos como desafio entender e revelar se a concepção de Lazer dos gestores e agentes sociais ${ }^{3}$ do Programa Esporte e Lazer da Cidade (PELC), no Município de Vitória - ES têm influência na eficiência, eficácia e efetividade social deste programa.

Tal análise foi realizada a partir do comparativo entre as diretrizes provenientes do Ministério do Esporte, e àquelas adotadas no âmbito municipal. Isso nos permitiu, em última instância, analisar a coerência entre as concepções de Lazer assumidas nessas duas esferas administrativas.

3. O termo "agente" foi utilizado neste trabalho para designar especificamente os professores/coordenadores que atuam diretamente nos núcleos, ministrando as atividades. Contudo, para o PELC, todo ator envolvido com a implementação deste projeto, desde a gestão, administração ou aplicação dos conteúdos recebe a denominação de agentes sociais de Esporte e Lazer. Esse conceito é exclusivo do PELC, não se aplicando aos outros projetos do Ministério do Esporte. 
A partir desta questão central, duas outras se levantaram: o que expressam a fala e os documentos originados pelos gestores acerca de sua concepção do Lazer e quais as relações entre essa concepção e as ações desenvolvidas na prática. Para respondê-las, realizamos uma pesquisa de natureza descritiva e os dados foram coletados por meio do Estudo de Campo, sendo analisados prioritariamente num caráter qualitativo.

Como fontes, utilizamos os documentos emitidos tanto pelo Ministério do Esporte quanto pelos gestores e administradores do PELC em Vitória, com vistas a compreender a concepção de Lazer presente, assim como as orientações condutoras da ação dos agentes que atuam nos núcleos.

Realizamos também entrevistas com o Secretário Municipal de Esportes de Vitória, com o Coordenador do PELC no município e com os agentes coordenadores de cinco dos oito núcleos existentes na ocasião. Foram utilizados dois roteiros distintos de entrevistas semiestruturados, um para gestores e outro para os coordenadores. Esta etapa foi realizada no local de trabalho de cada um, permitindo-nos identificar a relação entre o que era falado e as ações desenvolvidas. Todos os dados podem ser encontrados integralmente em Areias (2008).

Os documentos foram analisados a partir do seu próprio conteúdo e a análise das entrevistas foi feita de acordo com as técnicas de categorização e interpretação indicadas por Sourioux e Lerat (2002).

Diante do exposto, faremos a seguir uma breve explanação do referencial teórico que fundamentou a pesquisa, o detalhamento dos procedimentos adotados a partir da metodologia escolhida, e, por fim, nossas interpretações acerca das respostas encontradas desde as indagações iniciais.

\section{ACERCA DO ESTADO, DA POLÍTICA E DO LAZER...}

Para falar de Políticas Públicas, faz-se necessário um apontamento concreto da ideia de política assumida nesse trabalho, de inspiração gramsciana. Política é um termo que Gramsci utiliza em dois sentidos, um mais amplo e outro mais restrito. No primeiro sentido, "política identifica-se praticamente com liberdade, com universalidade, com toda forma de práxis que supera a mera recepção passiva ou a manipulação de dados imediatos". Nesse aspecto, é possível concluir que todas as esferas do ser social são atravessadas pela política (COUTINHO, 1989, p. 90-91).

Já em sua acepção restrita, política aparece como o conjunto de práticas e de objetivações que se referem diretamente ao Estado, às relações de poder entre 
governantes e governados. Assim, ela não se coloca como algo que compõe a essência do ser social, mas sim como algo historicamente transitório.

A teoria do Estado é suficientemente ampla para explicar diferentes concepções que foram produzidas a partir de observações e interpretações das formas de organização das sociedades, e sua abordagem não cabe nos limites desse texto. Para nós é suficiente tomar as contribuições de Bobbio (1982) para dizer que o Estado moderno desenvolve-se desde o modelo liberal, o qual passou por diversas transformações históricas, tendo entre seus principais críticos a tradição marxista, com suas igualmente diversas correntes; até os modelos contemporâneos que experimentamos e entre os quais devemos fazer nossas opções teóricas e políticas.

Nesse contexto, ratificamos que nossa opção inspirada em Gramsci, constituise como uma das formas de leitura da organização social e, nesse caso, de funcionamento das políticas públicas.

Gramsci (2004), autor de tradição marxista, caracteriza o Estado, em sentido amplo, como composto por duas esferas principais: a sociedade política (ou Estado coerção), por meio do qual a classe dominante detém o monopólio legal da repressão e da violência; e a sociedade civil, formada pelas organizações responsáveis pela elaboração e/ou difusão das ideologias, (sistema escolar, as igrejas, os partidos políticos, os sindicatos, as organizações profissionais, jornais, revistas, entre outros).

Acerca da constituição e organização da sociedade civil, Bobbio ( 1982, p. 30) afirma que, em Marx e Engels, a sociedade civil está presente na base estrutural da sociedade, ou seja, "momento do desenvolvimento das relações econômicas, que precede e determina o momento político". Contudo, em Gramsci, a sociedade civil estaria presente na superestrutura.

Para Gramsci (2004), a superestrutura é constituída por duas esferas essenciais: a "sociedade civil", isto é, o conjunto de organismos designados vulgarmente como "privados" e pela "sociedade política e/ou Estado", que correspondem, respectivamente, à função de "hegemonia" que o grupo dominante exerce em toda a sociedade e àquela de "domínio direto", que se expressa no Estado e no governo jurídico.

Portelli ( 1 977) afirma que, ao caracterizar a sociedade civil, Gramsci apresenta três aspectos pelos quais pode ser considerada, a saber: como ideologia da classe dirigente, abrangendo todos os ramos da ideologia; como concepção de mundo, difundida em todas as classes sociais; e ainda, como direção ideológica da sociedade, articulando-se como ideologia propriamente dita, a estrutura ideológica (organizações que a criam e difundem) e o material ideológico (instrumentos técnicos de difusão, como o sistema escolar, por exemplo). 
No que se refere à sociedade política, Gramsci (2004) a diferencia do Estado, afirmando que enquanto a primeiro se refere ao "consenso espontâneo", submissão das grandes massas da população à orientação do grupo fundamental, o segundo está relacionado ao aparelho de coerção estatal, que assegura "legalmente" a disciplina dos grupos que não consentem.

Nesse contexto, o Estado também pode ser definido como hegemonia associada à ditadura, ou hegemonia escudada na coerção, sendo tais ações identificadas como estratégias diferenciadas para garantir o domínio de classes. Coutinho (1989) reforça ainda que somente pela coerção, nenhum grupo poderia manter de forma durável sua dominação e qualquer ação impopular do Estado deve ser precedida da criação de uma opinião publica adequada, no intuito de dispersar qualquer ideia discordante daquilo que se pretende realizar.

As políticas públicas também são importantes instrumentos do Estado na busca por legitimidade. Entretanto, Prates e Prates (2005) destaca um importante aspecto acerca de tais ações: seu potencial contraditório. Para a autora, as políticas públicas se referem a um conjunto de estratégias que dizem respeito ao âmbito da reprodução, redistribuição e consumo social, e que objetivam a produção de bens e serviços sociais garantidos a todos os cidadãos de forma universalista e igualitária, mas que tem caráter contraditório, na medida em que se constituem em espaços de conformação e, simultaneamente, leva ao desenvolvimento de processos sociais imprevisíveis.

Ainda nesse sentido, Coutinho (2008) chama atenção para o fato de que, entender as políticas públicas exclusivamente como instrumento de dominação da burguesia sobre a classe proletária, reflete uma leitura mecanicista do marxismo, e por ser unilateral, desconsidera a própria noção de dialética. Como em outros âmbitos da vida social, a esfera das políticas públicas é permeada pela luta de classes e, por meio de suas lutas, os trabalhadores postulam direitos sociais que, uma vez materializados, são indiscutivelmente uma conquista.

Para tanto, a participação da sociedade civil nas decisões é fundamental. Pateman (1992) afirma que a teoria da democracia participativa defende que a experiência de participação desenvolve e forja a personalidade democrática, isto quer dizer que quanto mais se cria a cultura de participação, mais preparados os indivíduos estarão para tomar decisões e contribuir na condução da sociedade.

Quando a autora compara as possibilidades do trabalho e do lazer na promoção da educação à participação, afirma que o Lazer tem dificuldades em relação ao tempo do trabalho (muitas vezes consolidado em termos de associacionismo de classe). Seus argumentos centram-se na quase ausência de possibilidade do ócio para os trabalhadores nos tempos atuais, e na grande mercadorização, que perspectiva o Lazer mais como consumo do que como tempo/espaço de liberdade. 
De fato, os argumentos de Pateman ( 1992) são contundentes, especialmente se considerarmos a crescente individualidade identificada na sociedade contemporânea. Contudo, entendemos que as possibilidades de experiências coletivas de Lazer, no qual o exercício da autonomia em decisões grupais se torna possível, a possibilidade de prática participativa também é mais favorável e pode promover a "educação" desse comportamento, conforme encontramos em autores como Marcellino (2002); Mascarenhas (2003); Padilha (2006).

Em termos gerais, isso possibilitaria a melhora da organização política, do exercício de cidadania e a luta por democratização dos direitos. E é exatamente essa a perspectiva de lazer que defendemos.

$\mathrm{Na}$ contramão das possibilidades de trato do lazer como educação à participação, o pilar de sustentação das discussões acerca do Lazer tem sido, em especial, o fato de que este se constitui enquanto direito social ${ }^{4}$, presente no Art. $6^{\circ} \mathrm{da}$ Constituição Federal de 19885. No entanto, Padilha (2000) destaca que o status adquirido pelo lazer foi fruto de conquistas ao longo dos séculos em âmbito mundial. A luta travada por melhores condições de trabalho impulsionou a ampliação das reivindicações para o tempo fora do trabalho.

O que poderia ser legitimado apenas como uma conquista dos trabalhadores foi utilizado também como instrumento das classes dominantes para controlar o tempo e o corpo. O tempo, em princípio "livre", passa a ser também vigiado e ocupado com atividades funcionais à produção. Manter os corpos sadios, aptos e prontos para o trabalho era condição necessária a qualquer atividade a ser realizada fora dele (PORTER, 1992).

O lazer se insere no seio dessas contradições: entre a liberdade e o controle; a autonomia e a heteronomia. O Estado é impelido a participar também desse processo conflituoso, e como não é neutro, posiciona-se de modo a desequilibrar o jogo em favor do caráter utilitário e funcionalista do lazer.

Algumas ações no Brasil merecem destaque, por alterarem significativamente o modo de lidar com o Lazer. Exemplo notável é a criação dos Sistemas "S", SESI e SESC, SENAI e SENAC 6 . Segundo Neves (20 I0), a articulação entre estas instituições

4. Coutinho (2008) afirma que os indivíduos não nascem com direitos, sendo estes fenômenos sociais, resultantes da história. As demandas sociais, que prefiguram os direitos, apenas são satisfeitas quando assumidas pelas instituições que asseguram uma legalidade positiva. Contudo, o direito social é algo que antecede - e é mais amplo - do que o instituído nas Constituições, nos códigos, etc. Sua primeira expressão se dá sempre na forma de expectativas de direito, ou seja, de demandas que são formuladas, em dado momento histórico determinado, por classes ou grupos sociais.

5. Brasil (1988).

6. SESI: Serviço Social da Indústria; SENAI: Serviço Nacional de Aprendizagem Industrial; SESC: Serviço Social do Comércio; SENAC: Serviço Nacional de Aprendizagem Comercial. 
correspondeu a um esforço de racionalização do ambiente industrial e dos serviços dentro e fora do espaço de trabalho, estimulando a produtividade e o consumo e garantindo, ao mesmo tempo, a ordem social.

O Estado também utilizou dessa estrutura para alcançar as regiões periféricas do País no intuito de "valer-se do Lazer como elemento compensatório da deterioração das condições de vida, decorrentes do desenvolvimento urbano-industrial, verificadas entre as populações mais pobres." (MASCARENHAS, 2007, p. 22). $\mathrm{Na}$ atuação dos Sistemas "S", os conflitos eram sublimados em favor do espírito comunitário que se ambicionava criar.

Já na década de 1990, as políticas neoliberais ganham força no Brasil, acompanhando o movimento global. Assim, o modelo de Estado Intervencionista perde espaço para uma concepção de intervenção mínima nas questões sociais.

Entre as diversas ações no âmbito da economia, o governo diminui os impostos e a taxação sobre o capital, enquanto reduz significativamente os recursos a serem aplicados nas políticas sociais. O recuo do Poder Público no lidar com estas questões, abriu caminho para uma atuação livre do mercado, que pôde assim ampliar seu domínio sobre o conjunto de vida social (MASCARENHAS, 2007).

Nesse contexto, o direito de propriedade e os direitos do consumidor sobrepõem-se aos direitos sociais dos cidadãos e o lazer torna-se acessível apenas para uma minoria, apresentando-se como um tipo muito específico de propriedade, evidentemente não acessível a todos. Por isso, Padilha (2000) considera o capitalismo como um sistema fundamentalmente totalitário, que rege as vinte e quatro horas por dia da vida do trabalhador. A autora denuncia que enquanto os neoliberais apresentam em discurso o ócio como libertação, na prática, tomam-no como um dos mecanismos de reforço da exploração, assumindo de maneira dissimulada o controle sobre o tempo alheio.

Em meio às contradições presentes nas possibilidades de "uso" do Lazer apontadas nesse tópico, pensamos que ainda cabe ao poder público proporcioná-lo à população. De acordo com seus objetivos, o PELC se insere no bojo dessa tentativa, ou seja, de operacionalizar e tornar palpável a concepção de lazer como exercício de cidadania.

A produção recente no campo do lazer ${ }^{7}$ tem apontado indicativos de ações que podem favorecer as políticas de esporte/lazer como direito. Contudo, é ainda nebuloso o impacto efetivo que tal produção tem gerado nas ações do poder público.

7. Melo (2007); Isayama e Linhales (2008); Suassuna (2009); Liáo Júnior, Sampaio e Behmoiras (2009); entre outros. 


\section{O QUE NOS FOI DITO PARA ALÉM DAS PALAVRAS?}

Ancorados na perspectiva de encontrar na manifestação de uma Política Pública de Esporte e Lazer, neste caso o PELC, as iniciativas necessárias para sua execução eficiente, eficaz e que traga efetividade social (BELLONI; MAGALHÃES; SOUZA, 2003), vislumbramos mais uma vez as dificuldades que se levantam contra qualquer ação que visa beneficiar a população que mais depende da intervenção do poder público.

O objetivo apresentado pelo Ministério do Esporte para o PELC, pode ser assim sintetizado:

Suprir a carência de Políticas Públicas e sociais que atendam às crescentes necessidades e demandas da população por Esporte recreativo e Lazer, sobretudo daquelas em situação de vulnerabilidade social e econômica, reforçadoras das condições de injustiça e exclusão social a que estão submetidas ${ }^{8}$.

Pela proposta do Programa, cada Núcleo deve ter um coordenador e três estagiários que podem trabalhar os diversos interesses culturais do lazer ${ }^{9}$, respeitando as especificidades da comunidade e da população beneficiada. Os agentes recebem formação inicial e continuada para atuar e podem ter formação em diversas áreas de conhecimento, sendo admitidas inclusive pessoas da comunidade que estejam dispostas a atuar como "oficineiras".

Em Vitória, foram identificados quatro Núcleos: Parque Moscoso, Resistência, Mangue Seco e Tabuazeiro; e quatro Sub-Núcleos: Itararé, Bairro República, Atlântica Ville e Maria Ortiz. Contudo, apenas cinco destes foram visitados, seja por dificuldades quanto ao agendamento da visita ou pelo fato do núcleo não estar em funcionamento na ocasião.

Para as entrevistas com os gestores foram determinadas as seguintes perguntas norteadoras: ( 1$) \bigcirc$ que a prefeitura de Vitória tinha em mente quando submeteu seu projeto ao Ministério do Esporte para aprovação? (2) Em sua opinião, quais as aproximações entre o que o Ministério do Esporte propõe para o lazer e o que a gestão municipal pensa acerca do tema? (3) Faça um breve histórico da construção do projeto submetido ao Ministério.

Optamos por realizar uma entrevista semiaberta, na qual poderiam aparecer outros elementos que ajudassem a compreender nosso objeto. Nas entrevistas com os coordenadores, as questões fomentadoras foram: ( $\mathrm{I}) \bigcirc$ que você conhece

8. Rio Grande do Norte (2009).

9. Melo e Alves (2003); Marcellino (2002), entre outros, apresentam que são seis os interesses culturais do lazer: Manuais, Sociais, Turísticos, Intelectuais, Físico-esportivos, Artísticos. 
acerca do PELC? (2) Qual é a relação entre o Programa e o lazer de acordo com sua visão? (3) Que avaliação você faz da prática implementada em seu Núcleo, ou seja, ela é coerente com a proposta do PELC? (4) O que você faz no seu tempo livre que poderia ser caracterizado como lazer?

A partir dessas questões, buscamos a comunicação com os atores, preocupados em entender a concepção de lazer desses indivíduos. Os dois gestores entrevistados serão descritos como GI e G2; Os demais agentes, ou seja, os coordenadores dos núcleos serão nomeados a partir de $\mathrm{Cl}$ até $\mathrm{C} 4$. Considerando que dois núcleos possuem o mesmo coordenador, quatro entrevistas foram realizadas.

De modo geral, identificamos assim como afirma Marcellino (200 I), que são muitos os aspectos que influenciam no êxito de uma ação do Estado para o lazer, incluindo a formação do quadro profissional, a intersetorialidade das ações e, como nosso estudo buscou identificar, a concepção de lazer dos agentes e gestores envolvidos.

Como exemplo, podemos citar que no núcleo em que o entrevistado não havia passado pelo processo de formação do PELC, ficou evidente que o agente não conhecia os objetivos do programa e sua concepção de lazer resumiu-se a "lazer é aquilo que faz as pessoas se sentirem bem" (C4). Neste núcleo, pode-se observar uma adesão muito pequena por parte da comunidade, atividades não sistematizadas, o que acabou contribuindo para o fechamento do núcleo logo após a realização de nossa pesquisa.

Sem conhecer o projeto, seus objetivos e métodos, fica difícil que a comunidade participe do processo de legitimação da ação, sem a qual torna-se inviável alcançar efetividade social.

Quanto à análise das entrevistas, além do conceito chave que permeia nosso trabalho, buscávamos também perceber outras categorias e conceitos que se relacionam diretamente ao entendimento de Lazer. Sendo assim, a análise das entrevistas foi pautada na tentativa de perceber também o conceito de Política Pública de cada gestor e agente social entrevistado e de como suas compreensões tanto de lazer quanto de política pública se aproximam ou não da concepção de Estado que aqui adotamos.

A visão de Política Pública identificada nas entrevistas é de que se constitui como ação que passa a ser concebida como expressão da autonomia do cidadão, já que o Estado vem gradativamente abrindo mão de seu papel de interventor, gerando espaço para as iniciativas individuais e, potencialmente, para o setor privado se estabelecer. As falas a seguir deixam clara essa percepção:

As pessoas é que praticam o esporte e as pessoas que administram é que são responsáveis por oportunizar as vivências. A instituição é abstrata, os responsáveis são os gestores e os praticantes é que são os reais executores. (Gl) 
O que eu entendo da filosofia do PELC é estar fomentando o lazer onde ele já existe e estar levando para os locais onde ele ainda não existe, fazendo acontecer ou dando suporte para que continue acontecendo. (Cl)

A saída do Estado de cena condiciona a prática do Lazer ao poder aquisitivo, excluindo ainda mais os já "marginalizados" devido às condições materiais objetivas (MASCARENHAS, 2007).

Quando buscamos a concepção de Lazer compartilhada pelos entrevistados, percebemos que na maioria dos casos não existe grande discrepância quando comparados ao conceito presente nos documentos do PELC, sobretudo por parte dos gestores e nos núcleos cujos coordenadores passaram pelo processo de formação previsto para os agentes sociais de Lazer.

As características de prazer, espontaneidade e livre escolha das atividades a serem realizadas em um tempo de não trabalho estiveram presentes em grande parte das falas. A necessidade de se observar a realidade do local e os interesses culturais do lazer peculiares à população atendida, foi mencionada pelos agentes, conforme aparece na fala abaixo:

Lazer é a forma como as pessoas usam o tempo que tem disponível, que eles não estão usando para sobreviver. Eles querem fazer coisas para se sentir bem. A participação deles, a integração deles enquanto comunidade. Seja da forma que eles encontrarem. Uns gostam de praticar o esporte, outros gostam de dançar, outros gostam de se alongar, outros gostam de conversar. (G2)

Contudo, pudemos observar que nos diversos núcleos as atividades frequentemente limitavam-se à experiência direta dos professores e/ou coordenadores, especialmente ao conteúdo físico-esportivo. Por exemplo, o professor cuja experiência pessoal era a capoeira, priorizava este conteúdo nos dois núcleos em que atuava.

No núcleo que possuía quantitativo maior de estagiários, as atividades eram mais diversificadas, mas ainda assim restritas ao conteúdo físico-esportivo do lazer. Sendo assim, a concepção compartilhada a respeito do que é Lazer e do modo como este se manifesta demonstrou não ser o único fator relevante para a coerência entre as ações e os objetivos.

O quantitativo de estagiários disponibilizados para os núcleos não estão de acordo com a proposta original do Programa, e tem se demonstrado insuficiente para a realização de um trabalho mais qualitativo. Outros elementos também prejudicam o andamento do PELC, como por exemplo, a escassez de recursos, que acarreta numa estrutura física debilitada e insuficiência de materiais adequados. 
A própria percepção de alguns agentes a respeito de suas práticas parece negligente, na medida em que não operacionalizam o entendimento de que o Lazer a ser alcançado não é a pura recreação ou ocupação do tempo. Ao mesmo tempo em que avaliam que este projeto possibilita a transformação social por meio do Lazer, reconhecem que a transformação se dá apenas de modo paliativo, não havendo garantia alguma de que vai se preservar.

A dificuldade dos agentes em lidarem diretamente com as necessidades "extras" (fora do lazer) de cada um dos indivíduos atendidos também é um fator relevante, conforme demonstra o relato a seguir:

Aqui a gente passa a melhor das informações, pois a gente não ensina só o esporte, mas também a lidar com o dia a dia. Com as drogas, a bebida alcoólica. Com as meninas, tem a questão da sexualidade. E todos são orientados a estudar, até a terceira idade. [...] Tem aqueles que ouvem e aprendem, mas há aqueles que apenas passam por aqui, mas não absorvem. (C2)

Pelo que se vê tanto o que foi exposto das percepções de Política Pública, quanto a concepção de lazer materializada por parte dos agentes, parecem indicar que essas categorias se distanciam da ideia da apropriação e exercício do lazer como direito social e, portanto, também se distanciam de um modelo de Estado promotor desse direito. Trata-se de um Estado que pauta suas ações mais na legalidade do que na acessibilidade a direitos, conforme a fala abaixo:

Então, o que está na Constituição e que cabe ao Poder Público de executar é o que se caracteriza como dever do Estado [...]. Mas, foi esse dever que norteou isso aí, as garantias pra comunidade. (G2)

Diante do exposto, ao relacionarmos as categorias lazer e política pública da forma como são concebidas pelos agentes e as formas como são executadas nos núcleos do PELC, percebemos um modelo de Estado distante daquele de inspiração gramsciana que aponta para a cidadania compartilhada entre esse ente e a sociedade civil; e sua aproximaçã̃o de um modelo cujo papel limita-se a atenuar os efeitos da desigualdade social, sem, contudo, tentar eliminá-la.

\section{CONCLUSÕES}

Esse estudo se referiu a aspectos relevantes para a avaliação de políticas públicas, de modo especial indicados por Marcellino (2002) e Belloni, Magalhães e Souza (2003). Ao relacionar a indicação das duas referências, optamos por avaliar a concepção de lazer dos gestores como indicador de bom funcionamento de políticas públicas de esporte/lazer. 
No decorrer do trabalho, tanto pela empiria, como referendados pela construção teórica que norteou a pesquisa, vimos o quanto é difícil a avaliação por um indicador tomado isoladamente. Por isso, além de considerarmos nossos outros estudos que trataram da intersetorialidade e da formação de profissionais, como indicadores de bom funcionamento das Políticas Públicas de Lazer, também pudemos identificar a existência de um elemento que precede tais considerações, ou seja, o fato de que as ações do Estado estão inseridas em um contexto político, econômico e ideológico, não sendo isentas de sua interferência.

Quando se analisa separadamente os conceitos de Política Pública e Lazer, descolados de uma concepção de Estado, parece haver uma incoerência na percepção desses elementos, pois se por um lado o Lazer é visto como elemento de transformação, por outro o Estado e a Política Pública permanecem vinculados a noção de manutenção do equilíbrio social (a homeostase não induz a mudança).

Considerando a vasta produção acadêmica que buscou avaliar políticas públicas de lazer em diferentes contextos e regiões do Brasil, algumas delas citadas no corpo deste trabalho, podemos afirmar que essa realidade não tem necessariamente a ver com os representantes transitórios do poder, mas, com os pilares de sustentação das ações que são construídas a partir do modelo de Estado adotado, ou seja, capitalista e neoliberal.

Parece ter ficado claro que o PELC, assim como muitas políticas públicas, tem caráter contraditório. Se isso é verdade, concordamos com Prates e Prates (2005) que uma ação inicialmente de conformação, pode levar ao desenvolvimento de processos sociais positivos para a classe trabalhadora.

Não se pode perder de vista que a esfera das políticas sociais é permeada pela luta de classes em primeira instância, mas diversas outras disputas de poder estão presentes na sociedade. Portanto, apenas por meio de embates e de ocupação de espaços de participação, a população excluída poderá equilibrar a correlação de forças e conquistar o direito a acessar os direitos sociais, inclusive ao lazer.

\section{Public Policies for leisure in mediation between State and Society: opportunities and limitations}

ABSTRACT: This study is attempted to evaluate an action of the State with the society in the field of leisure, through its social eficiency and effectiveness (BELLONI; MAGALHÃES; SOUZA, 2003), using as an indicator one of the elements presented by Marcelinno (200 I): the conception that the managers have of leisure. For that, we took as a reference the Program of Sport and Leisure in the City (PELC) and sought to identify in the guidelines from the Ministry of Sport and in the actions observed in the council of Vitória - ES, the conception of leisure. KEYWORDS: Public Polic; leisure; social law; assessment. 


\section{Políticas Públicas para el ocio en la mediación entre el Estado y la Sociedad: oportunidades y limitaciones}

RESUMEN: Ese estudio se constituyó en la tentativa de valorar una acción del Estado junto a la sociedad en el área del ocio, a partir de su eficiencia, eficacia y efectividad social (BELLONI; MAGALHÃES; SOUZA, 2003), utilizando como indicador uno de los elementos presentados por Marcelinno (200 I ): la Concepción que los gestores tienen del ocio. Para eso, usamos como referencia el Programa Deporte y Ocio de la Ciudad (PELC) e intentamos identificar en las directrices provenientes del Ministerio de Deporte y en las acciones observadas en el Municipio de Vitoria-ES, la concepción del Estado, Políticas Públicas y, principalmente de Ocio.

PALABRAS-CLAVE: Políticas Públicas; ocio; derecho social; evaluación.

\section{REFERÊNCIAS}

AREIAS, K. T. V. Programa Esporte e Lazer da Cidade no Município de Vitória-ES: uma breve análise a partir da Concepção de Lazer dos Gestores. 2008. 126 folhas. Monografia (Graduação em Educação Física). Centro de Educação Física e Desportos, Universidade Federal do Espírito Santo, Espírito Santo, 2008.

BELLONI, I.; MAGALHÃES, H.; SOUZA, L. C. Metodologia de avaliação em políticas públicas. Tradução de Floriano de Souza Fernandes. São Paulo: Cortez, 2003.

BOBBIO, N. O conceito de sociedade civil. Tradução de Carlos Nelson Coutinho. Rio de Janeiro: Edições Graal, 1982.

BRASIL. Constituição ( 1988 ). Constituição da República Federativa do Brasil: promulgada em 5 de outubro de 1988. Brasília: Senado Federal, 1988.

CORREIA, M. V. C. Que controle social na política de Assistência Social? Serviço Social \& Sociedade, São Paulo, Ano XXIII, v. I, n. 72. p. 43-60, 2002.

COUTINHO, C. N. Gramsci: um estudo sobre seu pensamento político. Rio de Janeiro: Campus, 1989.

. Contra a corrente: ensaios sobre democracia e socialismo. São Paulo: Cortez, 2008.

GOVERNO DO ESTADO DO RIO GRANDE DO NORTE. Secretaria de Estado do Esporte e do Lazer. Programa Esporte e Lazer na cidade. Rio Grande do Norte, 2009. Disponível em: < http://www.seel.rn.gov.br/contentproducao/aplicacao/seel/acoes/gerados/an_esporte_lazer_da_cidade.asp>. Acesso em: 20 jan. 2009.

GRAMSCI, A. Cadernos do cárcere: os intelectuais. O princípio educativo. Jornalismo. V. 2.

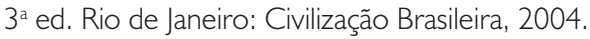


ISAYAMA, H. F.; LINHALES, M. A. (Org.). Avaliação de políticas e políticas de avaliação: questões para o esporte e o lazer. I. ed. Belo Horizonte: Editora da UFMG, 2008. v. I. 209 p.

LIÁO JUNIOR, R.; SAMPAIO, J. S.; BEHMOIRAS, D. C. Controle social na perspectiva do Programa Esporte e Lazer da Cidade. In: CONGRESSO BRASILEIRO DE CIÊNCIAS DO ESPORTE, I6., CONGRESSO INTERNACIONAL DE CIÊNCIAS DO ESPORTE, 3., Salvador, 2009. Anais... Salvador, 2009. p. I-9.

MARCELlinO, N. C. (Org.). Lazer e Esporte: Políticas Públicas. 2. Ed. Campinas: Autores Associados, 2001 .

2002.

. Estudos do lazer: uma introdução. 3. Ed. Campinas: Autores Associados,

MASCARENHAS, F. Lazer como prática de Liberdade. Goiânia: UFG, 2003.

MASCARENHAS, F. Outro Lazer é possível! Desafio para o Programa Esporte e Lazer da Cidade. In: CASTELLANI, L. (Org.). Gestão pública e política de lazer: a formação de agentes sociais. Campinas: Autores Associados, 2007. p. 17-40.

MELO, V. A. de; ALVES JÚNIOR, E. de D. Introdução ao lazer. Barueri: Manole, 2003.

MELO, M. P. O chamado terceiro setor entra em campo: políticas públicas de esporte no governo Lula e o aprofundamento do projeto Neoliberal de Terceira Via. Licere, Belo Horizonte, n. 10, v.2, p. I-35, ago. 2007.

MINISTÉRIO DO ESPORTE, GOVERNO FEDERAL. Orientações acerca da implementação do Programa Esporte e Lazer da Cidade. Brasília, 2007. Disponível em: < http://portal.Esporte.gov. br/sndel/Esporte_Lazer/projeto_social/orientacoes.jsp> . Acesso em: 20 de janeiro de 2009.

PADILHA, V. Tempo livre e capitalismo: um par imperfeito. Campinas-SP: Alíneas, 2000.

. Dialética do lazer. São Paulo-SP: Editora Cortez, 2006.

NEVES, L. M. W. (Org.). Direita para o social e esquerda para o capital: intelectuais da nova pedagogia da hegemonia no Brasil. São Paulo: Xamã, 2010.

PATEMAN, C. Participação e teoria democrática. Rio de Janeiro: Paz e Terra, 1992.

PORTELLI, H. Gramsci e o bloco histórico. Tradução de Angelina Peralva. $5^{a}$ edição. Rio de Janeiro: Paz e Terra, 1977.

PORTER, R. História do corpo. In: BURKE, P. (Org.). A escrita da história. São Paulo: UNESP, 1992. p. 29|-326.

PRATES, J. C.; PRATES, F. C. A contribuição da pesquisa para o desenvolvimento de políticas sociais pelo poder local. Textos \& Contextos, Porto Alegre, v. 04, n. I, p. I-18, dez. 2005. Disponível em: <http://revistaseletronicas.pucrs.br/fass/ojs/index.php/fass/article/ viewFile/l005/785>. Acesso em: 20 mar. 201 I. 
ROELDES, A. D.; BORGES, C. N. F; VEUNTURIM, L. F. Características Essenciais de Formação de Agentes Sociais para Garantir a Vivência do Lazer. In: SEMINÁRIO O LAZER EM DEBATE, I 0.,Belo Horizonte. Coletânea... Belo Horizonte: CELAR/UFMG, 2009. p. 297-305.

SILVA, M. O. S. e (Org.). Avaliação de políticas e programas sociais: teoria e prática. São Paulo: Veras, $200 \mathrm{I}$.

SOURIOUX, J. L.; LERAT, P. Análise de texto: método geral e aplicações no direito. Tradução de Joana Canêdo. São Paulo: Martins Fontes, 2002.

SUASSUNA, D. M. F. A. O programa esporte e lazer da cidade: a política de formação para o trabalho e o papel dos agentes sociais. In: CONGRESSO BRASILEIRO DE CIÊNCIAS DO ESPORTE, I6.; CONGRESSO INTERNACIONAL DE CIÊNCIAS DO ESPORTE, 3., 2009, Salvador. Anais... Salvador, 2009. p. I-I I.

VENTURIM, L. F; BORGES, C. N. F. Novas estratégias de gestão na Prefeitura de Vitória: o Programa Esporte e Lazer da Cidade e a intersetorialidade das ações. In: SEMINÁRIO DE GESTÃO ORGANIZACIONAL CONTEMPORÂNEA, 6., CONGRESSO DE TECNOLOGIAS DE GESTÃO E SUBJETIVIDADES, I., Vitória, 20 I0. Anais... Vitória: UFES, 20 I 0. p. 81-93.

Recebido: 25 nov. 2009

Aprovado: 22 dez. 2010

Endereço para correspondência:

Keni Tatiana Vazzoler Areias Avenida Hugo Musso, no 1692, apt 402

Bairro Praia da Costa

Vila Velha - ES

CEP: 29.101-280 